\title{
Saúde percebida em professores universitários: gênero, religião e condições de trabalho
}

\author{
Saúde percebida de professores universitários
}

\author{
Kátia Bones Rocha \\ Jorge Castellá Sarriera
}

\section{Resumo}

\begin{abstract}
A presente pesquisa investiga como os professores de uma universidade particular percebem sua saúde. O delineamento é de caráter descritivocorrelacional. Os instrumentos utilizados: Questionário de Saúde de Goldberg (QGS-60) e uma ficha com dados biodemográficos investigaram variáveis individuais e relativas à atividade laboral. A amostra se constituí de $16 \mathrm{I}$ professores, escolhidos por estratos através das diferentes área de formação. Os resultados revelam que os professores percebem que sua saúde geral está como de costume, ou seja, nem melhor nem pior e que existe associação entre as variáveis sexo, prática religiosa e variáveis relativas ao ambiente de trabalho (horas de trabalho na universidade e em sala de aula), influenciando a percepção que os professores têm de sua saúde.
\end{abstract}

Palavras-Chave: Professores universitários; Saúde percebida; Gênero; Contexto de trabalho.

\section{Perceived health of professors at private universities: gender, religion and work conditions}

\begin{abstract}
This research is looking into the way professors of private universities see their health. It was used the Goldberg's General Health Questionnaire (QGS60) and a form with biodemographic data that investigated individual variables related to the labor activity. These instruments were used to study the conditions of $16 \mathrm{I}$ professors chosen from different areas of study. It was used descriptive and correlational statistics for the data analysis. The study's results showed that the professors didn't see any change in their general health; in fact, it is neither better nor worse according to their opinion. And the results also showed that there are some different variables such as sex, religion, work environment and prolonged work hours influencing the professors' perception of their own health.
\end{abstract}

Key-words: University professors; Gender; Work environment.

\section{Salud percibida en profesores universitarios: género, práctica religiosa y del trabajo}

\section{Resumen}

Este trabajo investiga como los profesores de una universidad particular perciben su salud. La delineación es de carácter descriptivo-correlacional. Instrumentos utilizados: Questionário de Saúde de Goldberg (QGS-60) y una ficha con datos bio-demográficos investigando variables individuales y relativas a la actividad laboral. La muestra se constituyó de $16 \mathrm{I}$ profesores que fueron elegidos por estratos por medio de las diferentes áreas de formación. Los resultados revelan que los profesores perciben que su salud general está como de costumbre, o sea, ni mejor ni peor y que existe una asociación entre las variables sexo, práctica religiosa y variables relativas al ambiente de trabajo (horas de trabajo en la universidad y en sala de aula), influenciando la percepción que los profesores tienen de su salud.

Palabras-Clave: Profesores universitarios; Salud percibida; Género; Contexto de trabajo. 


\section{Introdução}

A compreensão da saúde e da doença como processo contribui para o desenvolvimento de estudos na investigação dos ambientes e de suas formas de organização assim como as repercussões da interação entre o ambiente e os indivíduos. A saúde é compreendida, neste estudo, como um processo de adaptação ativa do homem aos diferentes contextos nos quais encontra-se inserido destacando a relação entre ambiente de trabalho e saúde. Atualmente, há uma grande valorização do trabalho como fator essencial para a construção da identidade, da socialização e da dinâmica das relações sociais (Cattani, 2000; Ester \& Roe, 1999; Peiró, Pietro \& Roe, 1996).

A Saúde do Trabalhador surge como um campo de estudos interdisciplinares que possui como objeto de estudo o processo de saúde e doença dos grupos humanos relacionados ao trabalho (Dias, 1994). As modificações dos processos de trabalho, os avanços das novas tecnologias e as novas formas de organização do trabalho produziram um deslocamento do perfil das doenças relacionadas ao trabalho, destacando-se, na atualidade, doenças como hipertensão arterial, doenças coronarianas, distúrbios mentais, estresse e câncer, dentre outras (Mendes \& Dias, 1991). Sarriera (2003) ressalta que a saúde e a qualidade de vida se constituem hoje em prioridades que se almejam conquistar e defender frente às pressões ambientais.

Neste sentido, o conceito de saúde vem evoluindo para uma compreensão mais ampla, baseada não só no exame da saúde física, nos sintomas mas também na compreensão da importância da percepção subjetiva do sujeito a respeito do seu estado de saúde, de sua qualidade de vida e bem-estar, enfatizando os aspetos que podem fortalecer a saúde.

Cabe destacar que estudos brasileiros investigando - adoecimento de professores relacionado a sua atividade profissional têm sido desenvolvidos, estudos quantitativos com grandes amostras como em Codo e Batista (1999), Moura (2000), ou qualitativos por meio de entrevistas com pequenas amostras (Mosquera, 2000; Mosquera \& Stobäus, 1996; Nunes \& Teixeira, 2000). Nesses estudos, a necessidade do desenvolvimento de pesquisas foi destacado, buscando compreender quais variáveis individuais e de contexto podem estar influenciando o adoecimento destes profissionais a fim de buscar estratégias que possam contribuir na melhora do ambiente de trabalho dos professores.

O presente estudo investiga como professores universitários percebem sua saúde e identifica relações entre as variáveis individuais (sexo, idade, religião, estado civil, escolaridade, número de filhos) e as variáveis do ambiente de trabalho (anos de docência, atividades além da docência, trabalho mais voltado à graduação ou pós-graduação, número de horas de trabalho na universidade, número de horas em sala de aula) que podem influenciar a percepção que os professores têm de sua saúde.

\section{Método}

\section{Participantes}

A universidade particular, alvo dessa pesquisa, subdivide os seus cursos por setores de formação: filosófico-humanístico, sócio-jurídico-econômico, biomédico e técnico-científico. As áreas de formação definidas pela universidade foram eleitas como forma de estratificar a população. Para cada estrato, foram sorteados cursos por área, de forma a serem representativos. Os participantes desta pesquisa são 161 professores de 14 cursos superiores de áreas de formação diversificadas, sendo que foram distribuídos 692 questionários, obtendo um índice de retorno de 23, $26 \%$.

A amostra apresentou o seguinte perfil: em relação ao sexo, a distribuição foi de $56 \%$ do sexo feminino e $44 \%$ do sexo masculino. Pela idade, os professores que têm entre 31 anos e 50 anos são $58 \%$, com menos de trinta anos são $12 \%$ e entre $6 \mathrm{I}$ anos ou mais são $30 \%$. Destes, $59 \%$ são casados, $26 \%$ são solteiros, sendo que $15 \%$ são viúvos ou separados. A maioria dos professores têm filhos (60\%). Em relação à religião pode-se observar $80 \%$ dos professores são católicos e destes $46 \%$ se consideram praticantes.

Atendendo a idade das mulheres, $13 \%$ tem menos de 30 anos; $30 \%$ entre $31-40 ; 32,2 \%$ entre $4 I-50$; $22,2 \%$ entre $5 \mathrm{I}-60$ anos. Por estado civil, $52,2 \%$ são 
casadas; $30 \%$ solteiras e $16 \%$ separadas. Chama a atenção que $55,6 \%$ não tinha filhos, $35,6 \%$ com I ou 2 filhos, e $9 \%$ com 3 ou mais filhos. O perfil religioso se assemelha aos valores da Instituição onde trabalham, $52 \%$ se diz praticante ( $85 \%$ da religião católica). Sua qualificação é excelente, $83,3 \%$ possui mestrado, doutorado ou pós-doutorado.

Com relação aos homens, II,3\% com menos de 30 anos, $39,4 \%$ entre 31 e 40 anos, $35,2 \%$ entre 4 I e 60 anos e 14,I \% com mais de 60 . Seu estado civil se caracteriza por $67,6 \%$ casados, $9,9 \%$ separados e $21,1 \%$ solteiros. Tem filhos $70,4 \%$ do grupo, $38 \%$ I ou 2 filhos, $19,7 \%$ com 3 ou 4 e $2,8 \%$ com mais de 4. Sua qualificação profissional é alta, $8 \mathrm{I}, 2 \% \mathrm{com}$ mestrado, doutorado ou pós-doutorado. Sua prática religiosa é regular, $39,4 \%$ sendo que $74,6 \%$ se denominam católicos.

Se analisarmos comparativamente as diferenças entre o grupo de professores universitários do sexo masculino e feminino,podemos destacar que existem mais professores homens casados do que mulheres (diferença de 15\%), que a paternidade é mais freqüente entre os professores que a maternidade entre as professoras (diferença superior a $25 \%$ ) e que os professores são menos aderidos a práticas religiosas (- $12 \%)$ se comparado com as mulheres professoras universitárias.

No que se refere ao tempo de dedicação à docência, a maioria dos professores está há mais de 16 anos nesta atividade (41\%), sendo que $38 \%$ estão entre 6 e 15 anos. $O$ menor índice (20\%) encontra-se entre os que estão de $\mathrm{I}$ a 5 anos na docência. $\mathrm{O}$ número de anos de trabalho, especificamente, na universidade alvo desta pesquisa, possui as seguintes freqüências: $53 \%$ estão trabalhando, no máximo, há 10 anos. Entre II a 20 anos estão $25 \%$ e de 21 anos ou mais de trabalho na instituição estão $22 \%$.

O número de horas semanais que os docentes dedicam ao trabalho na instituição universitária se expressou da seguinte maneira: $43 \%$ dos professores trabalha até 20 horas semanais; $23 \%$ trabalham de 21 a 30 horas e $34 \%$ têm dedicação integral.

Outro dado levantado foi o número de horas que os professores se encontravam em sala de aula. Grande parte dos professores (37\%) está de II a 16 horas semanais em sala de aula, sendo que $35 \%$ estão mais de 17 horas. O menor percentual (28\%) encontra-se entre aqueles professores que têm até 10 horas em sala de aula por semana. A maioria dos professores desenvolve preferencialmente atividades junto à graduação (84\%), enquanto que $16 \%$ desenvolvem suas atividades preferencialmente junto à pós-graduação.

Os professores foram questionados acerca das atividades que são desenvolvidas prioritariamente dentro da universidade. A maioria dos professores (86\%) trabalha dando aula na graduação e no curso de pós-graduação, $8 \%$ na área de pesquisa e orientação e $6 \%$ na área administrativa.

Dos professores $60 \%$ desenvolve outras atividades laborais além da universidade. Destes, $40 \%$ trabalha até 5 horas fora da universidade, $12 \%$ até 15 horas e o restante $(52 \%)$, trabalha mais de 15 horas fora da universidade.

\section{Instrumento}

O instrumento utilizado foi o Questionário de Saúde de Goldberg (Pasquali, Gouveia, Andriola, Miranda, Ramos, 1996) e questões biodemográficas e laborais dos docentes que investigaram variáveis pessoais, familiares e relativas à atividade laboral.

O Questionário de Saúde Geral de Goldberg (GSG) foi projetado para identificar elementos da saúde psicológica, física e social do indivíduo, buscando que ele expusesse como percebe sua saúde atualmente. $O$ QSG é constituída por 60 itens que são respondidos numa escala Likert de quatro pontos. A escala inicia com questões mais neutras e segue conduzindo para itens psiquiátricos. Os resultados obtidos definem como, de modo geral, o indivíduo percebe a sua saúde na atualidade.

\section{Procedimento}

Para a coleta de dados foram feitos contatos com as direções das Faculdades e deixados nos escaninhos dos professores envelopes incluindo uma carta de apresentação, questionário e o termo de consentimento informado. Foi solicitado a entrega do material na secretaria da unidade, em envelope fechado, sem identificação e depositado numa caixa para tal. 
A presente pesquisa obteve a aprovação do Comitê de Ética da instituição na qual foi realizada. Foram seguidas as normas e exigências da legislação do Conselho Federal de Psicologia sobre normas éticas de Pesquisa em Psicologia.

As respostas ao questionário foram registradas na forma de banco de dados no programa estatístico SPSS (Statistical Package for Social Science). Foram realizadas análises descritivas e correlacionais.

\section{Resultados e Discussão}

\section{Professores universitários: como percebem sua saúde?}

Os dados da pesquisa mostraram que os professores percebem que sua Saúde Geral não apresenta ultimamente alterações, "está como de costume", ou seja, nem melhor, nem pior, tendo como média 3,17 sendo que todas as dimensões tiveram média 3, com algumas variações. A escala de Goldberg possui 4 pontos, dois pontos referentes à presença de distúrbios ( $I=$ muito pior do que de costume e $2=$ pior do que de costume), um ponto neutro ( $3=$ como de costume) e um que revela ausência de distúrbio ( $4=$ melhor do que de costume). $O$ fator que apresentou a maior média foi ausência do Desejo de Morte $(M=3,79)$, indicando que os professores não percebem sua vida como inútil ou sem sentido. Já o fator que apresentou a menor média foi Estresse Psíquico $(M=3,00)$, ou seja, alguns professores sentem-se tensos, irritados e impacientes (Tabela I).

\section{Gênero e Saúde}

A análise de comparação de médias para grupos independentes entre sexo e saúde (fator geral e fatores específicos) mostrou que as mulheres se comparadas com os homens apresentavam médias menores de saúde percebida nas seguintes dimensões: Saúde Geral, Estresse Psíquico e Distúrbios Psicossomáticos.

O fato das mulheres perceberem sua saúde geral como pior do que os homens, bem como mais estressadas e com distúrbios psicossomáticos pode ser compreendido a partir do papel que a mulher

Tabela I. Resultados das médias e desvio-padrão da Saúde Geral e seus fatores

\begin{tabular}{lcc}
\hline \multicolumn{1}{c}{ Fatores } & Média & Desvio-padrão \\
\hline Saúde Geral & 3,17 & 0,41 \\
Desejo de Morte & 3,79 & 0,38 \\
Stress Psíquico & 3,00 & 0,61 \\
Desconfiança no Próprio Desempenho & 3,06 & 0,41 \\
Distúrbios do Sono & 3,29 & 0,64 \\
Distúrbios Psicossomáticos & 3,09 & 0,54 \\
\hline
\end{tabular}

Valores de referência: 4 (sentir-se ultimamente com melhor saúde do que de costume); 3 (nem melhor nem pior); 2 (sentir-se pior de saúde do que de costume); I (sentir-se muito pior de saúde)

Tabela 2. Resultados significativos da ANOVA entre os fatores de Saúde Geral e sexo

\begin{tabular}{|c|c|c|c|c|}
\hline \multirow{2}{*}{ Fatores } & \multicolumn{2}{|c|}{ Média } & \multirow{2}{*}{$t$} & \multirow{2}{*}{$p$} \\
\hline & Homens & Mulheres & & \\
\hline Saúde Geral & 3,25 & 3,09 & $-2,40$ & 0,02 \\
\hline Estresse & 3,15 & 2,87 & $-2,87$ & 0,00 \\
\hline Distúrbios Psicossomáticos & 3,22 & 2,94 & $-3,37$ & 0,00 \\
\hline
\end{tabular}

Valores de referência: 4 (sentir-se ultimamente com melhor saúde do que de costume); 3 (nem melhor nem pior); 2 (sentir-se pior de saúde do que de costume); I (sentir-se muito pior de saúde) 
atualmente ocupa na sociedade. Barañamo (1992) destaca que independentemente das mudanças nos papéis do que é ser homem e mulher nas últimas décadas, dentro da unidade familiar, as responsabilidades familiares seguem sendo prioritariamente das mulheres, o que resulta na dupla jornada de trabalho que possui repercussões inegáveis para a saúde destas. A jornada dupla de trabalho se sustenta através da crença de que a mulher é o ser cuidador. Cabe destacar que as tarefas que integram o trabalho doméstico são muito diversas quanto a sua complexidade, indo desde a limpeza, alimentação, administração de recursos até o cuidado e educação dos filhos bem como de cuidar das pessoas doentes.

Embora possa parecer, o perfil das nossas professoras universitárias teriam 'melhores' condições de se dedicar à função docente do que as professoras de outros níveis de ensino (Moura, 2000), pelo fato de muitas não estarem casadas, não terem filhos, e possuírem uma qualificação de escolaridade excelente. Isso nos revela que a mulher, para atingir esse patamar de status - docente universitária sacrifica, muitas vezes, sua vida pessoal a fim de conquistar um espaço profissional que até há pouco tempo era um reduto masculino.

Soma-se a isto que o trabalho docente exige uma jornada dupla de trabalho, pois no espaço concreto da universidade não há tempo suficiente para desenvolver todas as atividades, tais como planejar aulas, corrigir provas e trabalhos. Assim, pode-se entender os dados do presente estudo que mostram que as mulheres apresentam níveis de saúde mais comprometidos. Estas professoras universitárias, além da pressão de seu ambiente de trabalho, provavelmente ainda possuem atividades delegadas socialmente que as remetem não a uma dupla jornada, mas sim a uma tripla jornada de trabalho.

Apesar desta tripla jornada de trabalho realizada por muitas mulheres, há variáveis que amortecem o efeito do estresse no trabalho. Kwon, Beatty e Lueg (2000) desenvolveram um estudo no Brasil com mulheres com cargos de gerência. Os dados apontam que as gerentes que possuem melhor satisfação em sua carreira, menos estresse com o trabalho, menos intenção de demissão, menos sintomas psicossomáticos e bem-estar emocional mais positivo, são aquelas que percebem valores organizacionais adotados na instituição na qual trabalham, pois esta prioriza tanto a vida pessoal quanto a profissional da trabalhadora, oportunizando um balanço equilibrado entre a esfera privada e profissional.

\section{Prática da religião e Saúde}

As pessoas que se consideram praticantes de religião frente às não-praticantes possuem melhores níveis de Saúde Geral $(p=0,03)$ e menos Desconfiança com o próprio desempenho $(p=0,0 \mathrm{I})$, assim como apresentam menos Distúrbios de Sono $(p=0,06)$.

Há uma tendência de considerar os efeitos das práticas religiosas na saúde dos indivíduos. Waite, Hawks e Gast (1999) assinalam que há uma correlação positiva entre a adoção de comportamentos saudáveis e o bem-estar espiritual. Assim, os achados apresentados corroboram os dados apresentados pela presente pesquisa.

Tabela 3. Resultados da ANOVA entre os fatores de Saúde Geral e prática de atividade religiosa

\begin{tabular}{lccccc}
\hline \multirow{2}{*}{ Fatores } & \multicolumn{2}{c}{ Média } & \multirow{2}{*}{$t$} & \multirow{2}{*}{$p$} \\
\cline { 2 - 3 } & Praticante & Não praticante & & \\
\hline Saúde Geral & 3,25 & 3,09 & 2,59 & 0,03 \\
Desconfiança no próprio desempenho & 3,15 & 2,97 & 2,52 & 0,01 \\
Distúrbios do Sono & 3,38 & 3,18 & & 1,85 & 0,06 \\
\hline
\end{tabular}

Valores de referência: 4 (sentir-se ultimamente com melhor saúde do que de costume); 3 (nem melhor nem pior); 2 (sentir-se pior de saúde do que de costume); I (sentir-se muito pior de saúde). 
A OMS incluiu um domínio denominado "religiosidade, espiritualidade e crenças espirituais" no instrumento genérico de Qualidade de Vida WHOQOL - 100 (World Health Organization Quality of Life instrument - 100 itens). Apesar destes itens terem se mostrado insuficientes para uma análise mais aprofundada (Fleck, Borges, Bolognesi \& Rocha, 2003), eles demonstram, ao mesmo tempo, um esforço para compreender o quanto espiritualidade, religiosidade podem influenciar no processo de saúde e doença das pessoas.

$O$ interesse limitado dos professores pelas questões ligadas à religiosidade tem raízes muito antigas. A dualidade cartesiana que cindiu corpo e mente como duas entidades dicotômicas foi solução para o impasse político que emperrava o desenvolvimento da ciência - a posição da igreja católica. Com a visão de homem dual (mente e corpo como realidades distintas), foi possível a ciência ficar com o corpo e a filosofia com a mente (Cassel, 1976). Alma, religiosidade são esferas consideradas pelos pesquisadores como muito importantes para os indivíduos, mas que a ciência não tem "permissão" para estudar. Paiva (1999) realizou um estudo a respeito da representação social da religião em docentes pesquisadores universitários e seus achados apontam que, por um lado, existem diversos objetos sociais que interessam ao grupo acadêmico como a arte, a política, o papel da universidade na sociedade, porém outros que parecem alheios aos interesses acadêmicos como a religião. Segundo os entrevistados, a religião, diferentemente da ciência, é uma opção de foro íntimo, respeitável, não possuindo uma linguagem comum, racional da ciência, considerada necessária para estabelecer, com suficiente amplitude, as delimitações éticas, influenciando o emocional e fazendo parte global da vida, inclusive do social.

No estudo realizado por Volpi (1994), os professores destacaram que em uma universidade, principalmente de cunho confessional, existe a necessidade desta adotar valores mais humanísticos e religiosos. Ao lado disso destacam, inclusive, o auxílio à própria igreja para essa avançar em questões de difícil resolução.
$\mathrm{Na}$ presente pesquisa, a prática religiosa aparece associada a melhores níveis de saúde pelo fato da universidade ser confessional e muitos professores sentem-se identificados com os valores da Instituição. No entanto, as questões relacionadas à influência da religiosidade na saúde das pessoas apresentam-se como uma variável que deve ser mais investigada.

\section{Ambiente de Trabalho}

Os dados revelam a relação ao número de horas semanais de trabalho na universidade: quanto maior o número de horas semanais trabalhadas menores são os níveis de Saúde Geral $(p=0,027)$. As diferenças (teste de Tukey post hoc) são, em primeiro lugar, os docentes com dedicação exclusiva $(M=2,77)$, seguido já com bastante diferença, e formando outro subfator, o grupo de 31 a 40 horas $(M=3,15)$ e os demais grupos de carga horária, diminuindo horas no ambiente universitário.

A apresentação de maiores Distúrbios de Sono $(p=0,04)$ percebidos pelos professores, com resultados na ordem das diferenças semelhante ao anterior, sempre destacando um subfator específico e de forma mais comprometida com aqueles que têm dedicação exclusiva $(M=2,75)$. Tendências que se manifestaram foram também nas diferenças quanto ao Estresse Psíquico $(p=0,06)$ e Desejo de Morte $(p=0.06)$, sempre destacando a dedicação exclusiva como um subfator diferenciado das outras cargas horárias, identificadas na tabela. A seqüência de médias, conforme aumento de número de horas, revelam a tendência de deterioração da saúde percebida.

Nunes e Teixeira (2000) destacaram, em um estudo desenvolvidos com professores universitários brasileiros, que mesmo os professores que possuem dedicação exclusiva na universidade acabam realizando trabalhos em casa, tais como: escrever artigos, preencher formulários para as agências financiadoras, entre outras atividades, uma vez que a universidade não se constitui em um espaço de trabalho no sentido de produção pessoal do professor. Mosquera e Stobäus (1996), no seu artigo sobre o mal-estar na docência, indicam algumas causas para este fenômeno, sendo que uma delas seria carência de tempo suficiente para realizar um trabalho adequado e trabalho 
Tabela 4. Resultados da ANOVA entre os fatores de Saúde Geral e número de horas semanais na universidade

\begin{tabular}{|c|c|c|c|c|c|c|c|}
\hline Fatores & $\begin{array}{c}\text { Menos de } 10 \\
\text { horas }\end{array}$ & $11 \mathrm{~h}$ a $20 \mathrm{~h}$ & $21 \mathrm{~h}$ a $30 \mathrm{~h}$ & $31 \mathrm{~h}$ a $40 \mathrm{~h}$ & $\begin{array}{l}\text { Dedicação } \\
\text { exclusiva }\end{array}$ & $F$ & $p$ \\
\hline Saúde Geral & 3,39 & 3,17 & 3,16 & 3,15 & 2,77 & 2,83 & 0,03 \\
\hline $\begin{array}{l}\text { Distúrbios do } \\
\text { Sono }\end{array}$ & 3,60 & 3,30 & 3,24 & 3,26 & 2,75 & 2,50 & 0,04 \\
\hline $\begin{array}{l}\text { Stress } \\
\text { Psiquico }\end{array}$ & 3,28 & 2,97 & 2,99 & 3,02 & 2,48 & 2,33 & 0,06 \\
\hline $\begin{array}{l}\text { Desejo de } \\
\text { Morte }\end{array}$ & 3,95 & 3,72 & 3,82 & 3,81 & 3,50 & 2,25 & 0,06 \\
\hline
\end{tabular}

burocrático que rouba tempo da tarefa principal que é o de ensinar.

Este trabalho, fora da universidade, torna-se facilitado pelo advento da informatização, resultando numa modificação do processo de produção. $\mathrm{O}$ trabalho a distância rompe fronteiras e se difunde na sociedade como um todo, mediante os terminais de computadores, inclusive os domiciliares, integrados por redes, podendo constituir um espaço de trabalho em qualquer lugar (Dupas, 200I). Os professores, em virtude da forma como seu trabalho se organiza, têm necessidade de realização de tarefas fora do espaço organizacional e podem deixar que ocorra a invasão do trabalho no espaço privado.

Os professores foram questionados, além do número de horas de trabalho na instituição, a respeito do número de horas semanais que estão em sala de aula especificamente. Neste sentido, os resultados mostram que, de modo geral, quanto maior o número de horas em sala de aula, maiores distúrbios de sono e maior estresse percebido assim como tendências a menores níveis de saúde geral e maiores de distúrbios psicossomáticos.

Os dados apresentados podem levar à seguinte reflexão: os professores que passam maior número de horas em sala de aula possuem uma maior sobrecarga de atividades, considerando a diversidade de atividades extras, tais como programar e preparar cada uma das aulas, elaborar provas, corrigir avaliações e trabalhos.

Chamlian (2003) desenvolveu uma pesquisa junto a um grupo de professores da Universidade de São Paulo e concluiu que, mais que uma formação pedagógica específica, a sensibilização para as dificuldades da tarefa de ensinar e a valorização institucional dessa atividade consistiriam em um grande

Tabela 5. Resultados da ANOVA e médias entre fatores de Saúde Geral e número de horas semanais em sala de aula

\begin{tabular}{lcccccccc}
\hline Fatores & $\begin{array}{c}\text { Menos de } 5 \\
\text { horas }\end{array}$ & $\begin{array}{c}6 \mathrm{~h} \mathrm{a} \\
10 \mathrm{~h}\end{array}$ & $\begin{array}{c}11 \mathrm{ha} \\
16 \mathrm{~h}\end{array}$ & $\begin{array}{c}17 \mathrm{~h} \mathrm{a} 21 \\
\mathrm{~h}\end{array}$ & $\begin{array}{c}22 \mathrm{~h} \mathrm{a} \\
27 \mathrm{~h}\end{array}$ & $\begin{array}{c}\text { mais de } \\
28 \mathrm{~h}\end{array}$ & $F$ & $p$ \\
\hline $\begin{array}{l}\text { Stress Psíquico } \\
\text { Distúrbios do }\end{array}$ & 3,16 & 3,06 & 2,86 & 3,13 & 3,19 & 2,53 & 2,26 & 0,05 \\
Sono & 3,52 & 3,39 & 3,15 & 3,24 & 3,56 & 2,76 & 2,26 & 0,05 \\
Saúde Geral & 3,29 & 3,23 & 3,08 & 3,22 & 3,33 & 2,85 & 2,22 & 0,05 \\
$\begin{array}{l}\text { Distúrbios } \\
\text { Psicosomáticos }\end{array}$ & 3,20 & 3,12 & 3,04 & 3,07 & 3,18 & 2,47 & 2,12 & 0,06 \\
\hline
\end{tabular}

Valores de referência: 4 (sentir-se ultimamente com melhor saúde do que de costume); 3 (nem melhor nem pior); 2 (sentir-se pior de saúde do que de costume); I (sentir-se muito pior de saúde). 
avanço para a formação de professores. $O$ autor propõe que essa sensibilização à dificuldade pedagógica tanto poderia ocorrer mediante a freqüência de disciplinas ou programas para essa finalidade, bem como poderia ser desenvolvida por uma equipe que congregasse professores mais experientes e iniciantes, de forma que as experiências fossem confrontadas e analisadas.

Esta discussão deveria ser fomentada dentro das instituições de ensino uma vez que se assume, na maioria das vezes, que o professor tem a obrigação de saber ensinar muito bem, não considerando que esta é uma habilidade que pode ser desenvolvida. $O$ ensinar deveria ser traduzido não apenas no transmitir conhecimentos, mas sim no desenvolver a capacidade dos alunos de pensar e resolver problemas de forma crítica e analítica.

O trabalho técnico relacionado à especificidade profissional de cada professor poderia ser realizado através do incentivo da instituição concedendo um certo número de horas para que os professores desenvolvessem atividades de intervenção. A parceria mais efetiva entre a universidade e a comunidade poderia ser fonte para o desenvolvimento de pesquisas bem como ajudaria na qualificação dos alunos e das aulas ministradas, além de ser uma forma direta de melhoria da qualidade de vida das pessoas envolvidas nestes projetos.

No Brasil, na atualidade, convivemos com duas visões de universidade que ilustram as contradições que esse nível de ensino enfrenta. A primeira está ligada à associação entre ensino e pesquisa e ao caráter mais cultural atribuído a seus ensinamentos, advindos da atividade de pesquisa. A segunda visão está relacionada às evoluções almejadas pela conjuntura sócio-econômica, necessitando de profissionais cada vez mais qualificados e flexíveis (Chamlian, 2003). Frente à discussão apresentada, podemos observar que a universidade atravessa um momento no qual repensa seu papel, sendo que os professores precisam desenvolver uma série de habilidades diferenciadas dentro da instituição, o que pode levá-los a um grande desgaste em função do seu exercício profissional.

\section{Considerações Finais}

Os achados do presente estudo destacam que as variáveis sexo, prática religiosa, horas de trabalho na universidade e em sala de aula são as mais associadas com percepção dos níveis de saúde pelos docentes do ensino superior. Apresenta-se a necessidade das mulheres e homens repensarem seus papéis sociais a fim de que as conquistas importantes realizadas pelas mulheres possam significar saúde e desenvolvimento.

Em relaçao a essas diferenças de percepçao de saúde entre homens e mulheres, seria interessante desenvolver pesquisas investigando porque as mulheres percebem sua saúde pior que os homens. Assim, as análises teóricas das possíveis causas poderiam ser contratadas. As questões relacionadas à religiosidade e sua relaçao com percepçao de saúde pelos professores universitários foram estudadas de maneira pontual no presente estudo, merecendo o desenvolvimento de estudos mais aprofundados sobre essas relações.

Outrossim, os aspectos do ambiente de trabalho docente foram os mais destacados, pois têm uma influência negativa sobre a percepçao de saúde deste profissional. Seria importante desenvolver estudos que identificassem características positivas do ambiente de trabalho que podem contribuir para melhorar a saúde dos trabalhadores.

Os dados conduzem, ainda, à reflexão de que quanto maior número de horas na universidade e em sala de aula, mais os níveis de Saúde Geral e Distúrbios do Sono pioram. Assim como, quanto mais horas de trabalho fora da universidade, melhores níveis de Saúde Geral, maior sensação de confiança no próprio desempenho, menor nível de Desejo de Morte. Logo, o ambiente de trabalho pode estar vivenciado de forma a haver um maior sofrimento, dependendo do maior número de horas dedicadas a este tipo de atividade profissional.

A partir destes achados, discutidos anteriormente, algumas estratégias podem ser pensadas para que os docentes universitários não venham a adoecer em função de seu trabalho. Existe a necessidade das instituições de ensino superior 
refletirem nos motivos pelos quais o ambiente de trabalho pode estar contribuindo para $\circ$ processo de adoecimento destes profissionais. Algumas questões já foram pontuadas, tais como possibilitar que as atividades relacionadas à docência possam ser realizadas na instituição evitando assim que o mundo do trabalho invada o espaço privado destes profissionais prejudicando sua qualidade de vida. Priorizar atividades nas quais estes, através do grupo, possam pensar estratégias para resolver as problemáticas ligadas ao seu fazer profissional, não buscando fortalecer a idéia de um professor ideal, mas daquele que através da cooperação, da equipe, consegue pensar modos alternativos de resolver questões complexas que se colocam no dia-a-dia, buscando uma comunicação não só entre a equipe de professores, mas também com as instituições, além dos próprios professores, através do diálogo, buscarem espaços de resistência e negociação para que o seu trabalho seja produtor de desenvolvimento individual e social. Futuras pesquisas podem ser desenvolvidas avaliando como mudanças no ambiente de trabalho de docentes podem influenciar na percepçao de saúde destes.

\section{Referências}

Barañano, M. (1992). Mujer, Trabajo, Salud. Madrid: Editora Trotta.

Cassel, E. J. (1976). The Healer's art. New York:J. P. Lippincott Company.

Cattani, A. D. (2000). Trabalho \& Autonomia. Rio de Janeiro: Petrópolis.

Chamlian, H. C. (2003). Decência na universidade: Professores inovadores USP. Cadernos de Pesquisa, I/8, $4 \mid-64$.

Codo, W., \& Batista, A. S. (1999). O que é burn-out. Em W. Codo (Org.), Educação Carinho e Trabalho (pp. 237-253). Petrópolis: Editora Vozes.

Dias, E. C. (1994). Aspectos Atuais da Saúde do Trabalhador no Brasil. Em J.T. Buchinelli (Org.) Isto é Trabalho de Gente? Vida, doença e trabalho no Brasil (pp.|38-156). Rio de Janeiro: Vozes.
Dupas, G. (200I). Ética e poder na sociedade de informação. São Paulo: UNESP.

Ester, P., \& Roe, R. A. (1999). Values and Work: empirical findings and theorical perspective. Applied Psychology: an international review, $48(\mathrm{I}), \mathrm{I}-2 \mathrm{I}$.

Fleck, M. P. A., Borges, Z. N., Bolognesi, G., \& Rocha, N. S. (2003). Desenvolvimento do WHOQOL, módulo espiritualidade, religiosidade e crenças pessoais. Revista Saúde Pública, 37, 446-455.

Kwon, U., Beatty, S. E., \& Lueg, J. E. (2000). Organizational values, work norms, and relational role behaviours: An empirical retail assessment. International review of retail, distribution and consumer research, 10, 40 I-416.

Mendes, R., \& Dias, E. C. (199I). Da medicina do trabalho à saúde do trabalhador. Revista de Saúde Pública, 25, 34I-349.

Mosquera, J. J. M. (2000). Pós-modernidade, cultura e professorado: uma análise da subjetividade docente. Educação, 4I, 3I-46.

Mosquera, J. J. M., \& Stobäus, C. D. (1996). O mal-estar na docência: causas e consequêencias. Educação - Porto Alegre, $31,139-146$.

Moura, E. P. G. (2000). Esgotamento profissional (burnout) ou sofrimento psíquico no trabalho: $O$ caso dos professores da rede de ensino particular. Em J. C. Sarriera (Org.), Psicologia Comunitária - Estudos Atuais (pp. 88-120). Porto Alegre: Sulina.

Nunes. M. L., \& Teixeira, R. P. (2000). Burnout na carreira acadêmica. Educação - Porto Alegre, 4I, I47-164.

Paiva, G. J. (1999). Representação social da religião em docentes pesquisadores universitários. Psicologia USP, 10 , 227-239.

Pasquali, L., Gouveia, V. V., Andriola, W. B., Miranda, F. J., \& Ramos, A. L. M. (1996). GSQ - Questionário de Saúde Geral de Goldberg (adaptação brasileira). São Paulo: Casa do Psicólogo.

Peiró, J. M., Pietro, F., \& Roe, R. (1996). El trabajo como fenômeno psicosociales. Em J. M. Peiró \& F. Pietro (Orgs.), Tratado de psicología del trabajo. Vol. II: Aspectos psicosociaes del trabajo (pp. 17-33). Madrid: Síntesis.

Sarriera, J. C. (2003). A Síndrome de Burnout: A saúde em docentes de escolas particulares. SINPRO - Sindicato Cidadão [On line]. Recuperado em 05/03/2004. www.sinpro-rs.org.br/cepep/index.asp\#reso. 
Volpi, M. (1994). Testemunho de professores sobre sua ação profissional e a responsabilidade social da universidade: docentes da PUCRS pensam sua universidade. Tese de doutorado, Pontifícia Universidade Católica do Rio Grande do Sul, Rio Grande do Sul, Brasil.
Waite, P. J., Hawks, S. R., \& Gast, J. A. (1999). The correlation between spiritual well-being and health behaviors. American Journal of Health Promotion, 13(3), 159- 162.

Recebido em: 20/10/2005

Revisado em: 14/09/2006

Aprovado em: 19/12/2006

Sobre os autores:

Kátia Bones Rocha (katiabonesrocha@yahoo.com.br) doutoranda em Psicologia pela Universidade Autônoma de Barcelona, Mestre em Psicologia Social pela Pontifícia Universidade Católica do Rio Grande do Sul e Especialista em Saúde Coletiva pela Escola de Saúde Pública RS.

Jorge Castellá Sarriera (sarriera@terra.com.br) é doutor em Psicologia, professor adjunto da Universidade Federal do Rio Grande do Sul e professor convidado no pós-graduação em Saúde Coletiva da Universidade do Rio dos Sinos

Endereço para correspondência Jorge Castellá Sarriera

Rua Álvares Mac hado, 120/502

90630-010 Porto Alegre - RS 